\title{
Pseudotrisomy 13 and autosomal recessive holoprosencephaly
}

\author{
Mary J Seller, Lyn S Chitty, Helen Dunbar
}

\begin{abstract}
Two sibs, diagnosed prenatally, had holoprosencephaly, midface hypoplasia, and normal chromosomes. The first fetus also had polydactyly. This sibship may represent an example of autosomal recessive pseudotrisomy 13 .

( $\mathcal{f}$ Med Genet 1993;30:970-1)
\end{abstract}

We have previously reported a fetus with holoprosencephaly, midface hypoplasia, premaxillary agenesis, polydactyly, and normal chromosomes ${ }^{1}$ and suggested, along with others, ${ }^{2}$ that such cases might be termed 'pseudotrisomy 13'. We now report a second affected fetus in the same family, in whom all features were present except the polydactyly.

This was the second pregnancy of a healthy, unrelated, white couple, the maternal and paternal ages being 33 and 49 years respectively. Because of the previous abnormal fetus, a detailed ultrasound scan was performed, and semilobar holoprosencephaly and facial clefting were observed. Termination of pregnancy was requested by the parents.

The male fetus (figure) was small for dates, and there was microcephaly, midface hypoplasia with ocular hypotelorism, absent nose, maxillary hypoplasia, premaxillary agenesis, a large midline cleft lip, and total central cleft palate. In addition, there was mild hypospadias, but no other external abnormalities; in particular, there was no polydactyly. All internal abdominal and thoracic organs appeared grossly normal, but intracranially there was semilobar holoprosencephaly, absent olfactory lobes, and hypoplastic optic nerves. The chromosomes were normal, 46,XY.

Parental chromosomes were studied with high resolution banding at the time of this second termination. The paternal karyotype was normal $46, \mathrm{XY}$ but that of the mother comprised four cell lines: $45, \mathrm{X} / 46, \mathrm{XX} /$ $47, \mathrm{XXX} / 48, \mathrm{XXXX}$ in the proportions $6 \%$, $85 \%, 8 \%$, and $1 \%$ respectively.

The two affected male sibs in this family are very similar, except for the absence of postaxial hexadactyly in the second fetus, which occurred on all extremities in the first. Holoprosencephaly is not an uncommon malformation, often associated with an abnormal karyotype involving a range of different chromosomes and types of aberration. In addition, both autosomal dominant and autosomal recessive forms of holoprosencephaly, without polydactyly, are well documented. The parents of our cases have been examined and have no minor features such as a single central upper incisor, suggestive of the dominant form, so our cases could be autosomal reces-

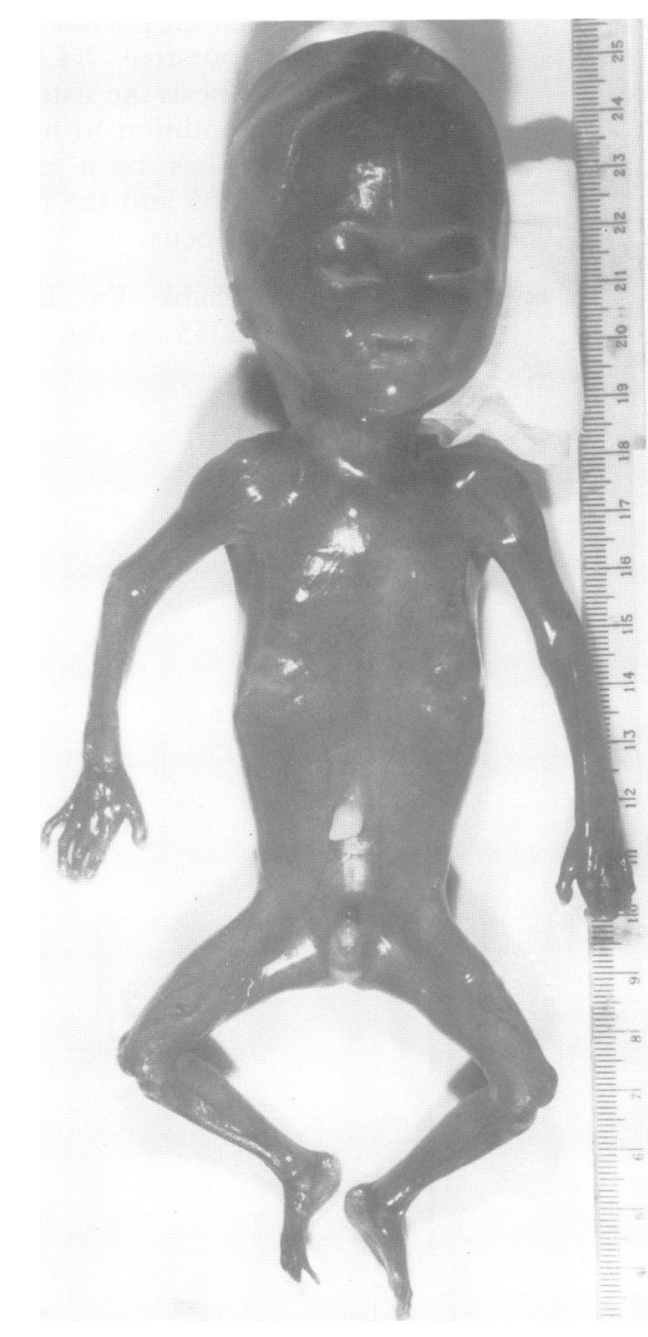

Fetus at 18 weeks with midface hypoplasia, absent nose, premaxillary agenesis, and midline cleft lip.

sive, although $\mathrm{X}$ linked recessive inheritance cannot be totally excluded. In some published autosomal recessive sibships, the craniofacial phenotype is similar, while in others there is a range of abnormalities from cyclopia to simply a median or lateral cleft lip. ${ }^{3}$ However, Cohen ${ }^{4}$ feels that the autosomal recessive type basically differs from the autosomal dominant form in that it mostly has severe manifestations.

It is only very rarely that polydactyly also occurs with this spectrum of defects when the chromosomes are normal: 11 cases of this so called pseudotrisomy 13 are documented. ${ }^{2}$ Two sibships have been described, ${ }^{56}$ both concordant for the polydactyly, but not for holoprosencephaly, although ocular hypotelorism or premaxillary agenesis and other craniofacial abnormalities were also present. It is possible that our family adds weight to the suggestion 
that pseudotrisomy 13 syndrome could be caused by a mutant gene showing autosomal recessive inheritance, ${ }^{2}$ and that there is a variable phenotype which overlaps with the previously recognised holoprosencephaly with normal chromosomes but without polydactyly. However, it is noted that the two sibships, as well as our own, were male, and of the single cases reported only two are females. We regard the maternal X chromosome mosaicism in our case as incidental to the findings in the fetuses.
1 Hewitt BG, Seller MJ, Bennett CP, Maxwell DM. Holoprosencephaly, polydactyly and normal chromosomes: pseudotrisomy 13? Clin Genet 1989;36:141-3.

2 Cohen MM Jr, Gorlin RJ. Pseudo-trisomy 13 syndrome. $\mathrm{Am}$ f Med Genet 1991;39:332-5.

3 Cohen MM Jr. Perspectives on holoprosencephaly. Part I. Epidemiology, genetics and syndromology. Teratology 1989;41:211-35.

4 Cohen MM Jr. Perspectives on holoprosencephaly. Part III. Spectra, distinctions, continuities and discontinuities. $\mathrm{Am}$ f Med Genet 1989;34:271-88.

5 Atkin JF. A new syndrome with cyclopia and trisomy 13 features. Am f Hum Genet (Suppl) 1988;43:A143.

6 Bachman H, Clark RD, Salahi W. Holoprosencephaly and polydactyly: a possible expression of the hydrolethalus syndrome. f Med Genet 1990;27:50-2. 